\title{
Application of 3D WebGIS and real-time technique in earthquake information publishing and visualization
}

\author{
Boren Li $\cdot$ Jianping Wu $\cdot$ Mao Pan $\cdot$ Jing Huang
}

Received: 14 October 2014/Accepted: 7 April 2015/Published online: 16 June 2015

(C) The Author(s) 2015. This article is published with open access at Springerlink.com

\begin{abstract}
In hazard management, earthquake researchers have utilized GIS to ease the process of managing disasters. Researchers use WebGIS to assess hazards and seismic risk. Although they can provide a visual analysis platform based on GIS technology, they lack a general description in the extensibility of WebGIS for processing dynamic data, especially real-time data. In this paper, we propose a novel approach for real-time 3D visual earthquake information publishing model based on WebGIS and digital globe to improve the ability of processing real-time data in systems based on WebGIS. On the basis of the model, we implement a real-time 3D earthquake information publishing system-EqMap3D. The system can not only publish realtime earthquake information but also display these data and their background geoscience information in a 3D scene. It provides a powerful tool for display, analysis, and decisionmaking for researchers and administrators. It also facilitates better communication between researchers engaged in geosciences and the interested public.
\end{abstract}

Keywords Earthquake - Real time - Virtual globe . WebGIS

\footnotetext{
B. Li $(\bowtie) \cdot$ J. Wu $\cdot$ J. Huang

Institute of Geophysics, China Earthquake Administration,

Bejing 100081, China

e-mail: borenli@cea-igp.ac.cn

J. Wu

e-mail: wjpwu@cea-igp.ac.cn

J. Huang

e-mail: huangj@cea-igp.ac.cn

M. Pan

School of Earth and Space Sciences, Peking University, Beijng, China

e-mail:panmao@pku.edu.cn
}

\section{Introduction}

Significant earthquakes often lead to loss of life, destruction of infrastructure, and consequently economic loss. However, earthquake prevention and mitigation require handling of complex data, including various spatial and temporal scales, historical records, real-time monitoring, and subsequent analytical results. Scientific and effective organization of the information is needed. As a tool for integrating multisource data, GIS has a profound impact on disaster risk reduction and provides the possibility of twoand three-dimensional (2D/3D) visual analysis of massive geospatial and hazard data (Abdalla and Tao 2004; Paar and Clasen 2007). It also increases the efficiency and effectiveness of hazard management. As a part of hazard management, earthquake disaster researchers have used GIS to facilitate disaster management. Researchers use WebGIS to assess hazards and seismic risk (Zerger and Smith 2003; Pessina and Meroni 2009; Sato and Harp 2009; Hashemi and Alesheikh 2011) and to share valuable information resources with the public by publishing various analytical seismic results on the Internet and elsewhere. Historical seismic data can also be analyzed with GIS (Cubellis and Carlino 2004; Pessina and Meroni 2009). For post-earthquake transportation, optimum pathways are rapidly obtained using GIS-based systems (Cao et al. 2009; Saadatseresht et al. 2009).

Although GIS is widely used in earthquake monitoring and prediction, it also enables to improve earthquake damage prevention, situation assessment, post-earthquake emergency relief, and so forth. Nevertheless, these systems are insufficient when dealing with seismic data, namely timely (real-time or near real-time) publishing and visualization of seismic information. Existing GIS-based 
application systems are weak in processing dynamic data, such as the latest seismic events, or the calculation of seismic intensity after an earthquake (Yu and Gong 2012). Most existing systems based on WebGIS use two-dimensional (2D) maps (JMA 2015; USGS/NEIC 2014; IRIS 2015), that is, using earthquake information and terrain layers to simulate real earthquake environment. The simulated environment are widely different from three-dimensional (3D) world that people actually experience.

To meet the needs of earthquake emergencies and postearthquake disaster mitigation, we propose in this paper a new solution to the real-time problem for GIS that integrates WebGIS, a temporal model, and 3D graphical user interfaces to provide real-time display and analysis tool for earthquake disaster mitigation. We propose a four-tier model for the real-time 3D visual earthquake information publishing based on WebGIS and virtual globe. This model consists of four layers: acquisition, database service, application service, and visualization layers. The acquisition layer collects real-time seismic data. The database service layer is responsible for managing real-time data and spatial data together with nonspatial data. The application service layer retrieves data from the database service layer, pushing real-time data to the client by means of the visualization layer, and provides map services. The visualization layer dynamically renders data from the application service layer for the client. This includes rendering vector data, massive amounts of image data, and terrain data in 3D scenes. Although different technologies are available to implement visualization of a 3D scenario, they comprise two types: one based on web-page techniques, such as Virtual Reality Modeling Language (VRML) (Bell et al. 1995; X3D, 2015); WebGL 2013); the other based on clients such as Google Earth (GoogleEarth 2015) and World Wind (2014). VRML and X3D require prior installation of a browser plug-in. Using technologies based on X3D, Shi et al. (2008) developed an earthquake disaster prevention and mitigation system. However, WebGL 3D can display contents directly in a web browser without additional settings. The client mode, that is, Google Earth and World Wind, can offer more powerful and functional experiences to users. Based on this model, we have developed a realtime earthquake publishing system. Here, we describe the system architecture and focus on the representation and rendering of seismic events as real-time data in the 3D scene.

This paper is organized as follows. We first present our model in Sect. 2 and then implement this model in Sect. 3. In Sect. 3.1, we describe the system architecture. In Sect. 3.2, we present 3D visualization of earthquake information. Section 4 gives some examples of application of the system. We conclude with a summary of our work in Sect. 5.

\section{3D WebGIS-based real-time information publishing model}

With the development of seismic sensors, transmission networks, computer hardware, and software, a digital seismic observation networks for seismic monitoring can now provide a variety of real-time information, such as real-time waveforms, gravity, underground fluids, and crustal deformation. In addition, as another type of realtime data, the earthquake situation, disaster management, and emergency decision support information management system provide real-time analysis and data dissemination of the earthquake situation, earthquake prediction, or disaster-area range. To manage and analyze these data of different types and spatial characteristics, we use GIS because it characteristically integrates and visualizes multisource data.

In this paper, we integrate real-time data collecting and processing with traditional GIS (Gong et al. 2014) and propose a novel approach for a real-time 3D visual earthquake information publishing model based on WebGIS and digital globe. The model unifies dynamic data publishing with static spatial data over a network and vividly displays processed data in $3 \mathrm{D}$ virtual scenarios. It provides a general solution of assembling seismological and spatial data by way of standard services for seismology.

This model consists of four tiers or layers: acquisition, database service, application service, and visualization, as shown in Fig. 1. The acquisition layer collects real-time seismic information. It consists mainly of various real-time information receivers. The receiver modules retrieve the

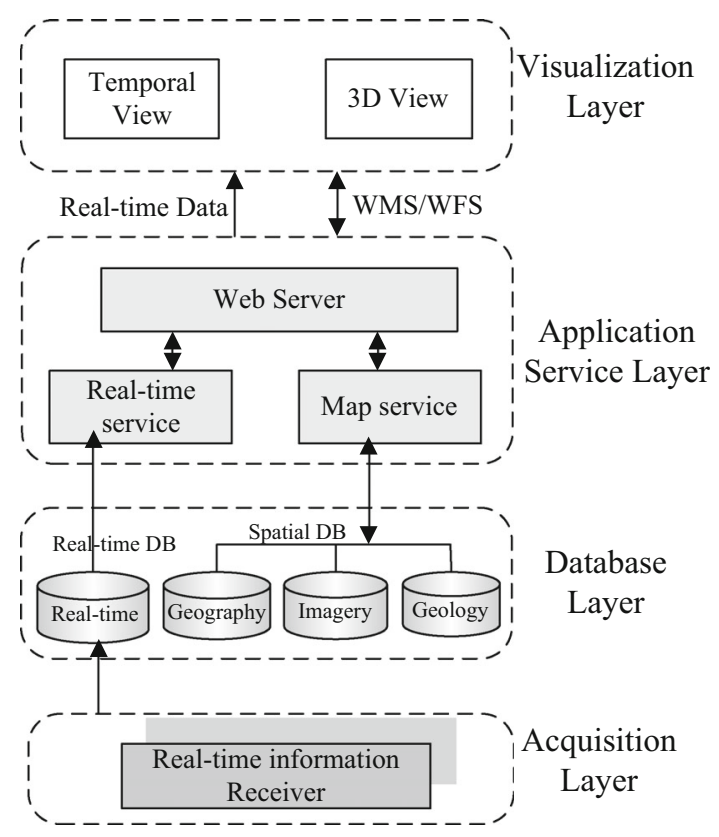

Fig. 1 Real-time 3D WebGIS architecture 
information from organizations such as the U.S. Geological Survey (USGS 2014), the China Network Center (CENC 2014), real-time seismic network monitoring and analysis systems, and earthquake early warning systems and push the data into the database layer. The acquisition layer differs the tiers of a general WebGIS system in that can automatically real-time collect data, whereas the tiers of the WebGIS system lack the appropriate function. The database layer deals with two different types of spatial information: real-time and static data. The real-time data are managed by real-time database, such as a seismic events database. The static data are managed by spatial database, such as cartographic maps, remote sensing images, digital elevation models, faults, and plate boundaries, which cannot be changed in a short time. The application service layer is key to the architecture of the model. It retrieves data from the database layer and publishes the processed result using the visualization layer. It provides two services: realtime service and a map service through a web server. Realtime service filters the real-time data from the database layer and converts the data into a unified format, whereas the map service offers Open Geospatial Consortium (OGC) Web Map/ Feature Service (WMS/WFS). The visualization layer performs two functions: temporal and 3D map displays. The temporal view dynamically represents real-time data, that is, earthquake events and current status of seismic devices, which are pushed from the application service layer. Three-dimensional (3D) map view mainly renders the $3 \mathrm{D}$ scene using vector data, remote sensing images, and terrain data. The two components can be combined into a $3 \mathrm{D}$ visual client or web browser, that is, a virtual globe, from which users can interactively access remote resources with operation requests and display the results of the comprehensive information. The layer integrates various data and expresses the virtual reality of the geographic area in focus, improving the representation of seismological information.

The model has the ability to collect, analyze, and disseminate real-time earthquake information, obtained from organization websites or automatic processing systems, such as earthquake early warning (EEW) systems, which generate earthquake information, shake maps, and alert information. It can also easily be extended to a range of types of real-time data, such as gravity, underground fluids, and crustal deformation merely by adding new real-time receiver modules, and is not limited to post-earthquake information.

\section{Implementing a real-time 3D earthquake publishing system}

\subsection{System components}

Based on a previous model, we have developed a real-time 3D earthquake information publishing system, EqMap3D, which can rapidly collect, transfer, integrate, and display earthquake information and massive amounts of multiscale spatial data over a network. The system has four components (Fig. 2), similar to the four-tier architecture in the publishing model described previously.

The EqMap3D system receives the seismic information from real-time data sources in three systems: Earthquake Instant Messaging (EQIM), Prototype Earthquake Early Warning System (PEEWS), and ShakeMap. The EQIM (Yang and Huang 2009) system official timely issues alerts regarding the latest seismic events from CENC over the Chinese seismic network after large earthquakes in China and other regions of the world. PEEW (Peng et al. 2011) produces alert messages for the Beijing capital region $\left(36^{\circ} \mathrm{N}-42^{\circ} \mathrm{N}, 113.5^{\circ} \mathrm{E}-120^{\circ} \mathrm{E}\right)$ after a medium or large earthquake $\left(M_{1}>3\right)$. The earthquake information generated from the two systems includes three elements of a typical seismic event: origin time, epicenter, and magnitude. These data are stored in the real-time database based on the PostgreSQL/PostGIS database (OSGeo 2010; Obe and Hsu 2011). Table 1 shows the data structure in the form of tuples or sets of ordered elements, stored in the database. It clearly shows that the earthquake information has both spatial and temporal characteristics. In addition, we extended the earthquake information to contain strong ground motion information by enabling the platform to dynamically receive raw grid data from the ShakeMap system (Chen et al. 2010) via a new ShakeMap receiver

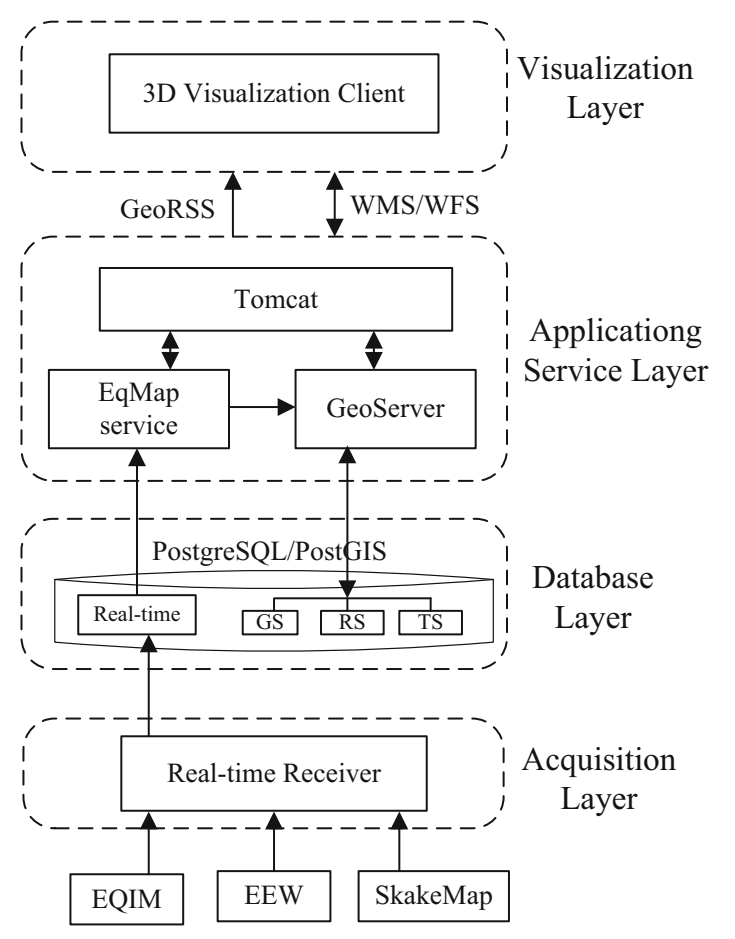

Fig. 2 Real-time 3D earthquake information publishing system architecture 
Table 1 The data structure of earthquake information

module. Because the raw grid data are only intermediate results of the represented strong ground motion information for map display, the data are not stored in the real-time database, but are directly pushed into the application service layer in the platform. The raw grid data are handled with spatial interpolation in the EqMap3D service module and then placed into the GeoServer (2014) to generate maps. Then the maps are distributed over a network with the Web Map Service (WMS) protocol and stored in the PostgreSQL/PostGIS database.

Besides the real-time data mentioned above, the system contains massive amounts of spatial data stored in the spatial database based on PostgreSQL/PostGIS as static data. It stores vector and raster data, that is, administrative divisions, roads, remote sensing imagery, and elevation. Currently, the data constructing the spatial database contain mainly the vector data such as 1:1,000,000 details of China's major transportation systems, rivers, and administrative points; raster data such as globe terrain elevation data SRTM30 (90 m), global Blue Marble Next Generation (BMNG) satellite imagery $(8,2$, and $0.5 \mathrm{~km})$, global Landsat7 satellite imagery $(15 \mathrm{~m})$; a catalog of global earthquakes $\left(M_{1}>5\right)$ from 2008 to 2013; and 1:4,000,000scale active Chinese tectonics as tectonic and seismic activity data. These data can be published as web service content by the GeoServer (2014) map server following the OGC WMS/WFS standard.

To disseminate real-time earthquake information (not including ShakeMap), the data should be formatted to support convenient exchange. Geodata can use typical Extensible Markup Language (XML)-based techniques for exchanging, that is, Geography Markup Language (GML), Keyhole Markup Language (KML), Geo Really Simple Syndication (GeoRSS), and JavaScript Object Notation (JSON)-based (GeoJSON) in web. We have adopted the GeoRSS-GML (Kresse and Danko 2012) format to encode the latest earthquake information because it widely supports various coordinate reference systems. Figure 3 shows an example of the content of the latest seismic event using the GeoRSS feed that we consider in this paper.
The published data are used by a 3D-visualization client (discussed in the next section). The viewer can simultaneously visualize various server map layers in the client, including such spatial data as cities, roads, rivers, faults, and the latest seismic events, and historical large earthquakes as spatiotemporal data, as shown in Fig. 4.

\subsection{D visualization for earthquake information}

The 3D visualization client uses virtual globe technology to render real-time earthquake information and massive realworld vector, imagery, and terrain datasets. To researchers, World Wind (NASA World Wind 2014) (released in 2004) is an attractive open-source 3D interactive viewer because its plug-in architecture enables users to easily add plug-ins and customize according to their requirements, compared to the commercial software Google Earth. Importantly, it is also a lightweight client because it accesses the necessary image and elevation from the backend NASA World Wind server across the Internet and downloads only those data that are required to display the view requested by the user. It and its server compose the client/server architecture (C/ S). However, World Wind has several limitations, such as system security (privacy issues in distributing data) and functional interoperability (cross-platform interoperable standards).

The client was developed using the Java program language, which is easily deployed easily on any machine. We use the World Wind Java software development kit (2011) as the basic library for rendering 3D geospatial scenes. However, we modify and add functional parts to the SDK for applications in seismic research that specify our local map server instead of the NASA map server, providing satellite images, terrain elevation data, and place name services. In addition to terrain and image data, the client retrieves other geologic data such as faults and trends of seismic activity provided by the application service layer (Fig. 2), and it builds various layers depending on the research topics of users.

Visualization of earthquake information can present not only the properties of a seismic event itself but also the characteristics of the specific area related to a seismic event. Visualization is important because, when additional information on the earthquake emerges, it can be used as a further evidence with which to anticipate damage to the area in an emergency response scenario, such as mountain landslides caused by earthquakes. The construction of the $3 \mathrm{D}$ topography of an area is performed by the 3D visualization client which uses the visualizing layer of the EqMap3D platform (Fig. 2). This layer receives data from the application service layer.

Temporal visualization is one of the most important features in spatiotemporal information systems (Nadi and 


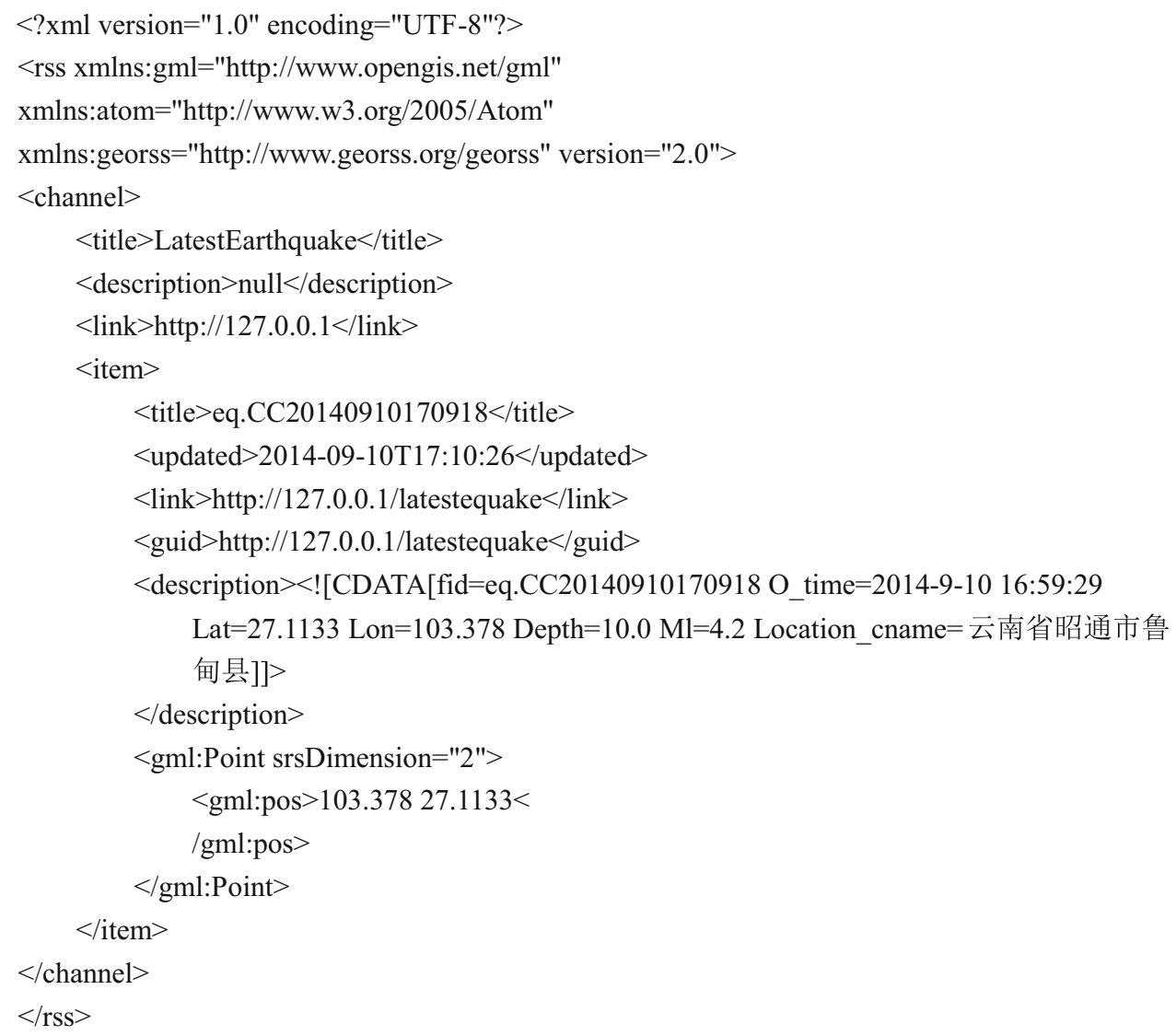

Fig. 3 An example of a GeoRSS feed for the latest earthquake information

Delavar 2003), because it can dynamically display data. We recognize three categories for a spatiotemporal object: positional, geometric, and attribute changes over time and combinations thereof. A new seismic event represents a combination type because it has a new location (position changes) and corresponding attributes (attribute changes). Changes in spatial position can be represented intuitively using different points in space. As such, changes in attributes can be displayed through visual mapping variables such as symbol size. This representation model can dynamically display the spatial location and state of an object, that is, earthquake changes with time. Changes in the position of an earthquake and aftershocks can be visually displayed on demand by the use of colors and shapes to visualize the status of the earthquake, that is, time and magnitude. In our publishing system, in addition to displaying the position of a seismic event, we use color to identify the time of its occurrence and size and shape to identify its magnitude.

Seismic events comprise three main elements: time, location, and magnitude. In essence, earthquake information is spatiotemporal because it combines spatial, temporal, and nonspatial attributes. To integrate real-time data into the 3D visualization client in the EqMap3D system, we add the GeoRSS parser into the visualization library. Then, we use a special layer to store the parsed real-time data, which can refresh its content in a timely manner, similar to the dynamic link layer in Google Earth. Finally, the spatiotemporal objects, that is, seismic events, that are stored in the layer are displayed in the 3D visualization client.

\section{Application of the system}

The EqMap3D system is a powerful information service platform for emergency response that receives, stores, processes, integrates, publishes, and displays real-time earthquake information. In particular, it can display the earthquake information in a 3D virtual globe scene and provide user interactivity, including easy browsing, zooming, and layer operations at multiscales and in real time, realistically reflecting the latest earthquake and environmental context. It is not only a tool for analysis of 


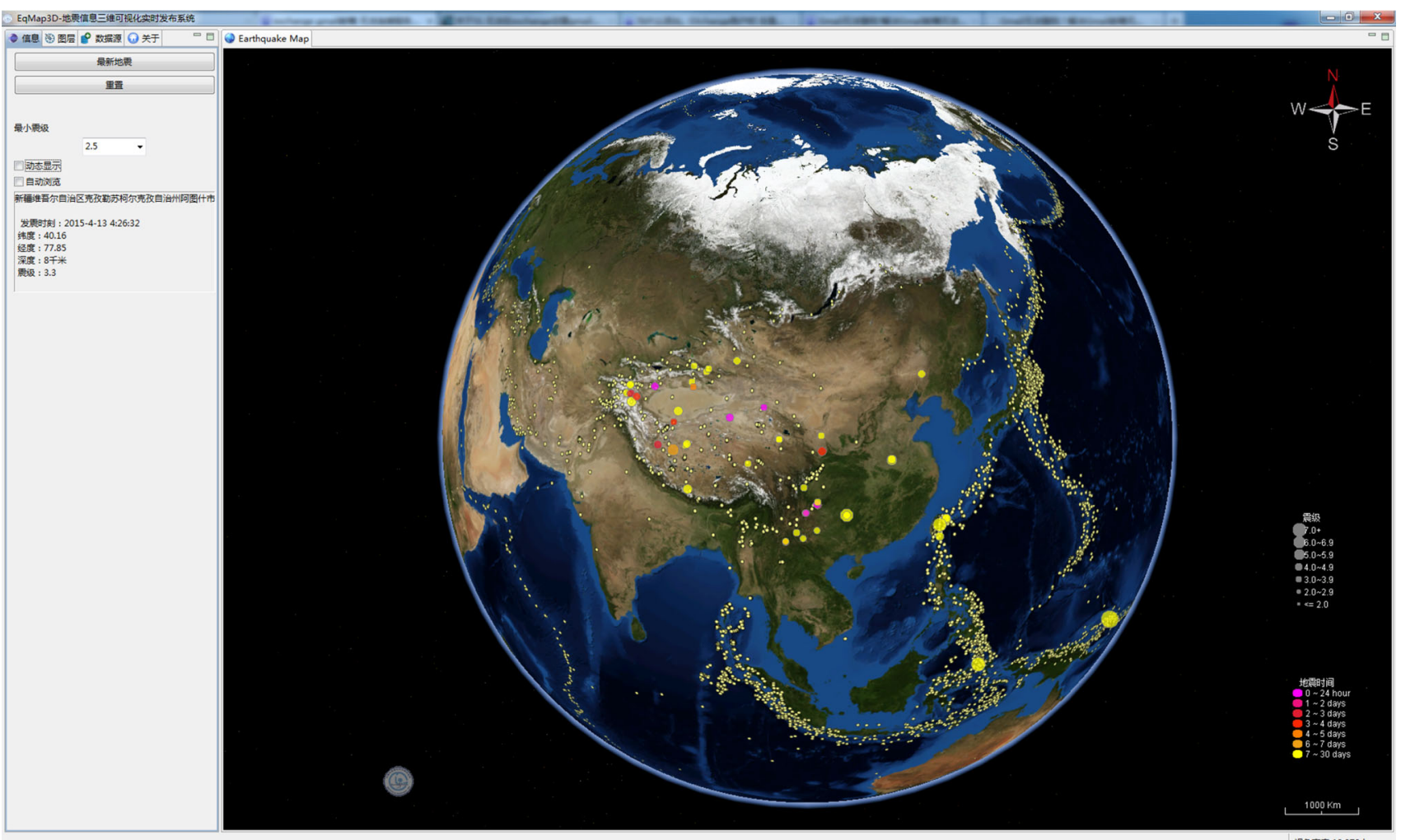

Fig. 4 The 3D visualization client of the real-time 3D earthquake publishing system

earthquake information but also, and more importantly, a venue for communicating research information and findings to the public. Seismological researchers can visualize their own data through the platform.

The system has been deployed in the Institute of Geophysics, China Earthquake Administration and disseminates real-time earthquake information and visualization of seismic analysis to inform the emergency response.

The system was first applied to an $M_{\mathrm{S}} 7.3$ earthquake occurred in Yutian County, Xinjiang Province on February 12, 2014 for analysis of the earthquake scenario (Fig. 5). When the receiver module in the system (Fig. 2) obtained the formal report of the earthquake occurrence from the EQIM system, the 3D visualization client of the system automatically navigated to the epicenter, automatically displayed the topography, terrain features, and geological faults in the vicinity of the epicenter area from the air at an angle. The raw data of rapid shaking intensity for the earthquake were published by the application service layer after being processed through the analysis module of the system (Fig. 6). The extent of the damage caused by the earthquake can be seen in the 3D scene, based on predicted ground motions. By scaling and viewing the geological features of shaking intensity IX and VIII areas, We can recognized the affected area of unhibited and mountainous.
Figure 7 shows an $M_{\mathrm{S}} 6.5$ earthquake occurred in Ludian County, Yunnan Province on August 3, 2014, with satellite images at different resolutions for the area of 3D topography. Figure 7 a shows the terrain conditions around the epicenter using Landsat7 satellite images with a resolution of $15 \mathrm{~m}$ at a scale of 1:2000. Figure $7 \mathrm{~b}$ shows the landforms around the epicenter when using high-resolution image landscapes at a scale of 1:50.

As shown above, the system offers not only a rapid display platform for real-time seismic events and the predicted distribution of strong ground motions but also geoscientific background information visualized in 3D by which the epicenter, magnitude, geographic, and geologic contexts, and potential geologic hazards are easily understood. In addition, the system facilitates accurate estimation of the degree of seismic risk for the disaster management and decision-making response such as the visualization of the ShakeMap data.

\section{Conclusions}

By providing comprehensive information in earthquake risk scenario analysis, GIS technology can increase decision-making efficiency in earthquake disaster mitigation. 


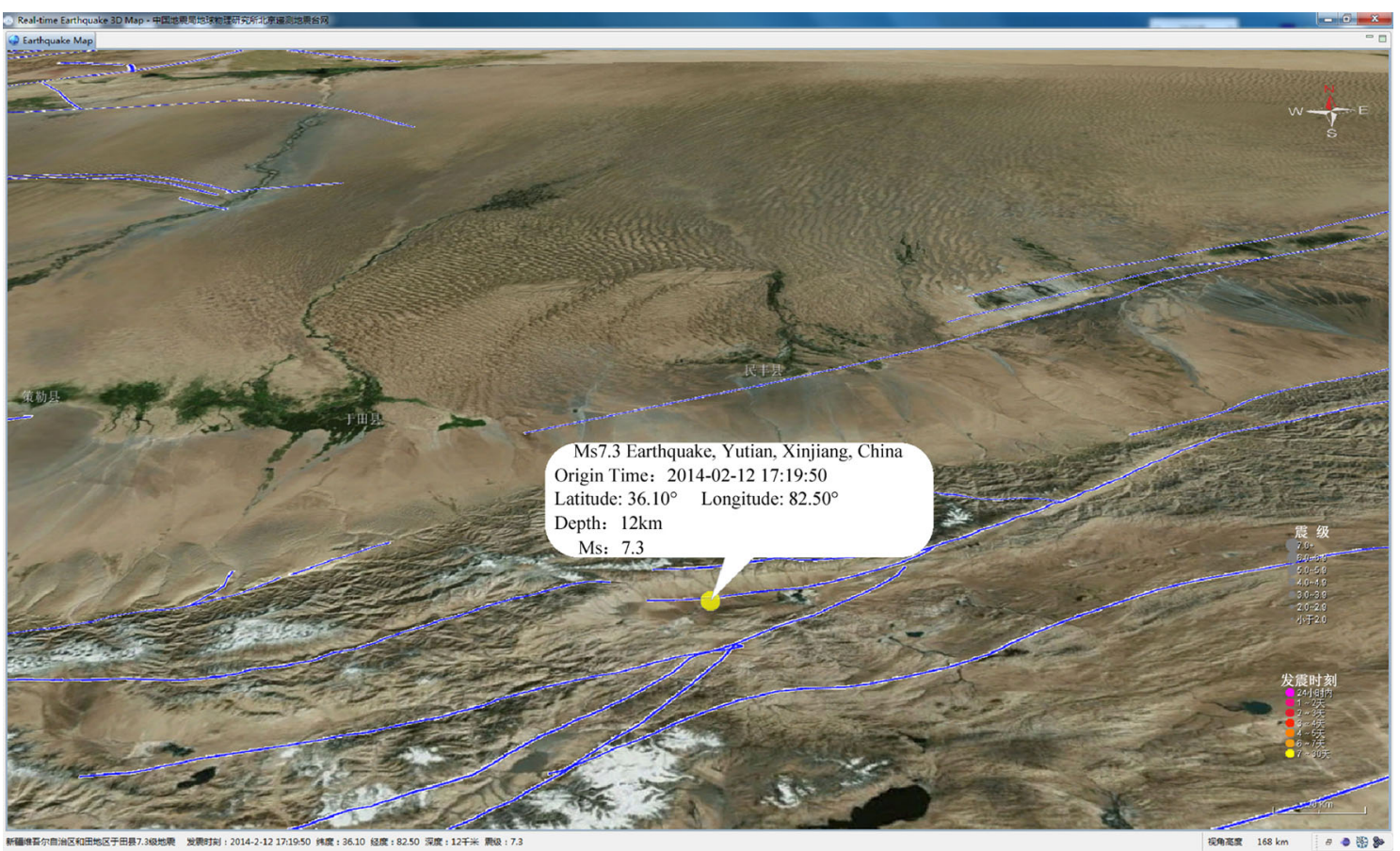

Fig. 5 The Yutian $M_{\mathrm{S}} 7.3$ earthquake occurred at 17:59:50 (LT) or 09:59:50 (UTC) on February 12, 2014, near a fault zone, is shown in the 3D visualization client

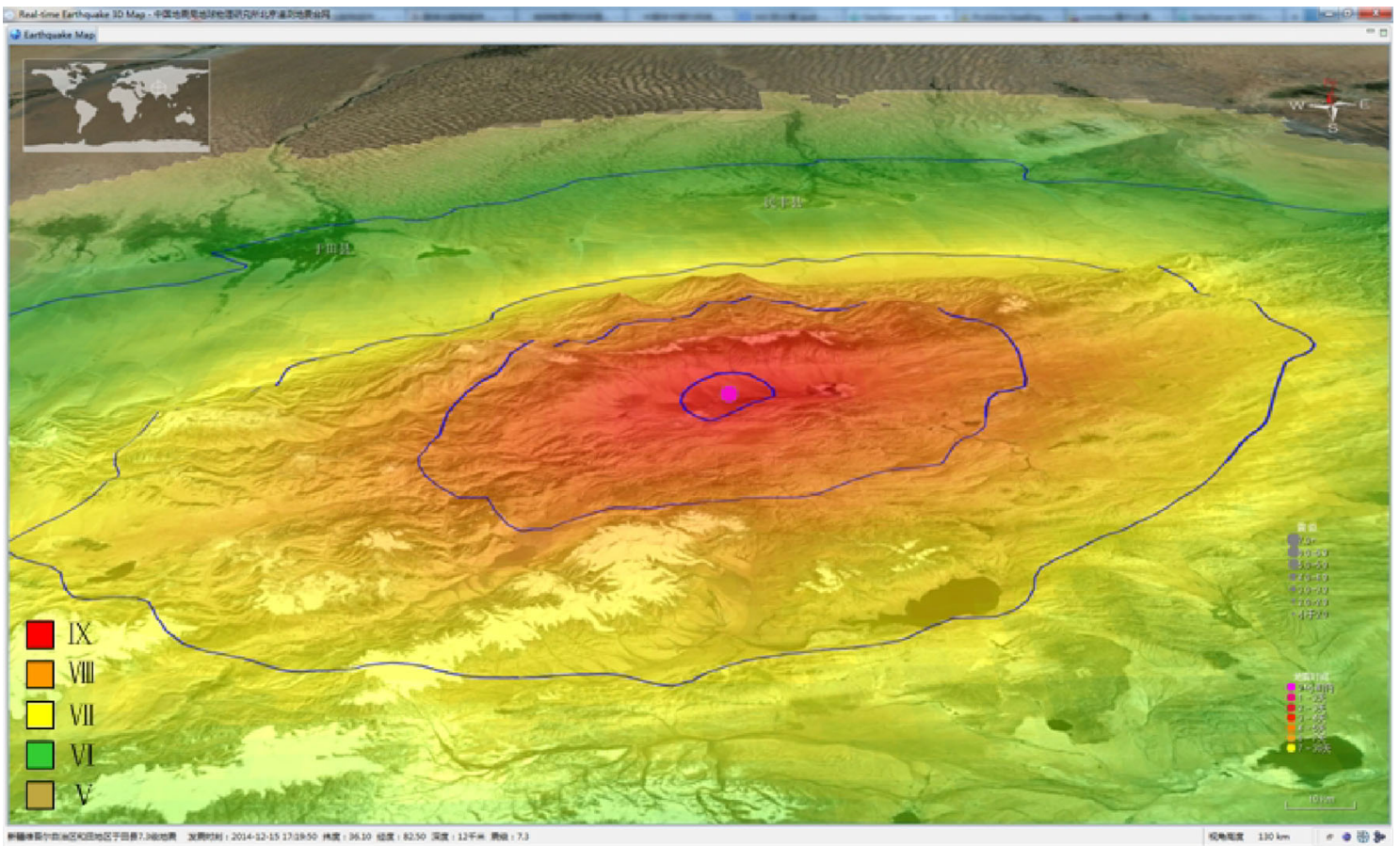

Fig. 6 The ShakeMap published $35 \mathrm{~min}$ after the Yutian $M_{\mathrm{S}} 7.3$ earthquake

In this paper, we propose first a novel model that combines conventional WebGIS and real-time techniques into a real-time 3D information publishing system. It consists of four components: an acquisition layer, a database layer, an application service layer, and a visualization layer. This system avoids the deficiencies of WebGIS in 

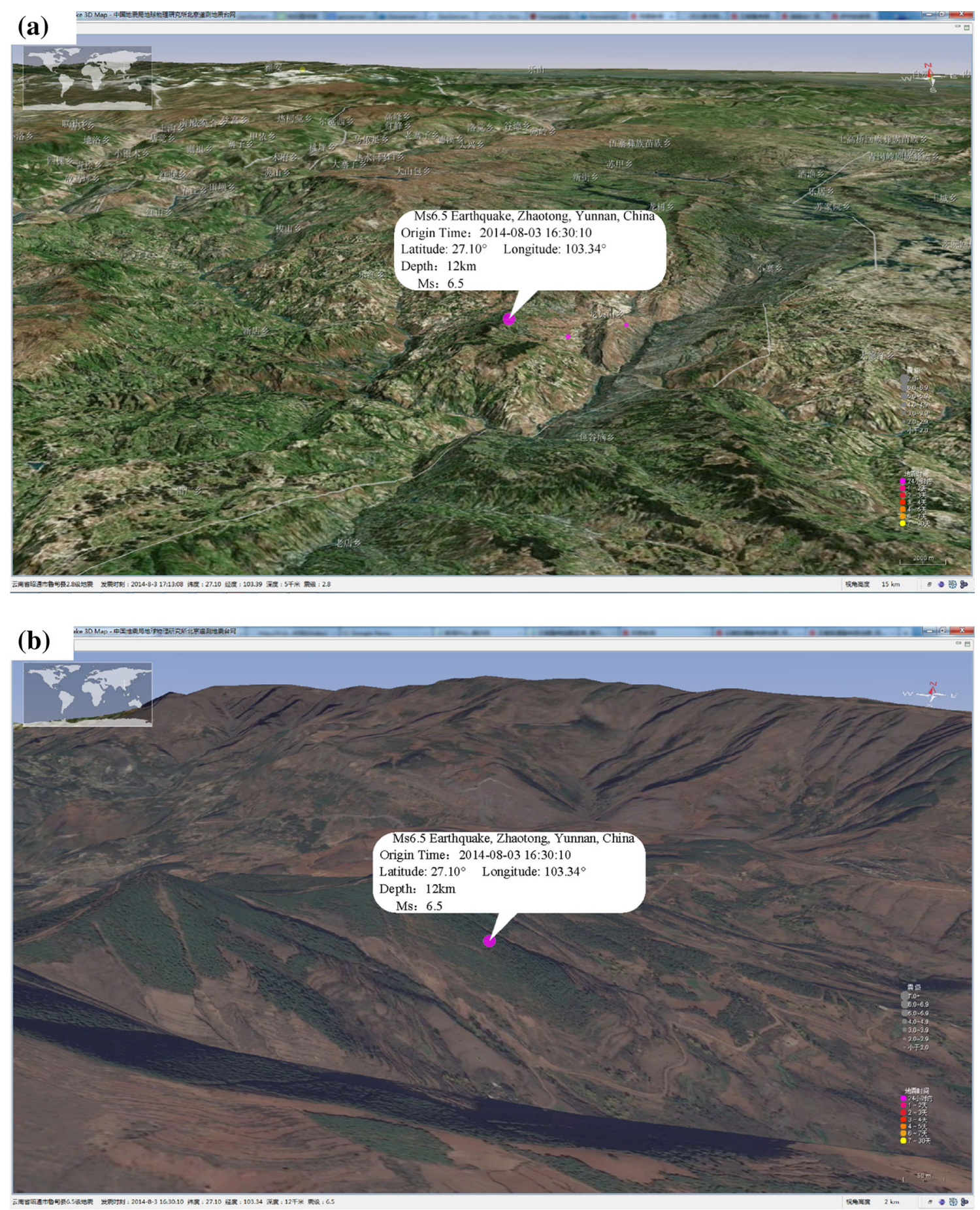

Fig. 7 The Ludian $M_{\mathrm{S}} 6.5$ earthquake that occurred at 16:30:10 (LT) or 08:30:10 (UTC) on August 3, 2014, automatically loading different resolutions remote sensing images at different scales

dealing with dynamic data, enabling seamless integration of real-time data and GIS. It also offers real-time 3D visualization of composite data for earthquake event and geoscience data. Based on this model, we developed a real- time 3D earthquake information publishing system and described its architecture. For the seismic event as a type of spatiotemporal data, we use dynamic temporal visualization to display the data in $3 \mathrm{D}$ scenarios. Our system 
provides instant earthquake information publishing with 3D GIS, which reduces the time-cost of decision making in damage mitigation.

For future work, we plan to improve the processing of real-time data, that is, progressive ground-shaking maps in time lapse. This will enable rapid and efficient access to seismic hazard and risk data.

Open Access This article is distributed under the terms of the Creative Commons Attribution 4.0 International License (http://creativecommons.org/licenses/by/4.0/), which permits unrestricted use, distribution, and reproduction in any medium, provided you give appropriate credit to the original author(s) and the source, provide a link to the Creative Commons license, and indicate if changes were made.

\section{References}

Abdalla R, Tao V (2004) Applications of 3D web-based GIS in earthquake disasters modeling and visualization. Geospat Inf Res Bridg Pac Atl 2:814-817

Bell G, Parisi A, Mark P (1995) The virtual reality modeling language: version 1.0 specification. http://www.web3d.org/x3d/ specifications/vrml/VRML1.0/index.html. The VRML Consortium Incorporated. Accessed 2014

Cao Z, Wang W, Ma D, Su J, Gao Z and Han Y (2009) Optimum path analysis of post-earthquake transportation considering multiobjective based on GIS. In: International conference on transportation engineering 2009, ASCE, pp 1104-1109

CENC (2014) Latest earthquakes. http://www.csndmc.ac.cn/. China Earthquake Networks Center(CENC). Accessed 2014

Chen K, Yu Y, Gao M (2010) Research on ShakeMap system in terms of the site effect. Earthq Res China 26(1):92-102 (in Chinese with English abstract)

Cubellis E, Carlino S (2004) Management of historical seismic data using GIS: the Island of Ischia (Southern Italy). Nat Hazards 33(3):379-393

GeoServer (2014) GeoServer user manual. http://docs.geoserver.org/ 2.3.0/user/. Open Source Geospatial Foundation (OSGeo). Accessed 2013

Gong J, Li X, Wu H (2014) Spatiotemporal data model for real-time GIS. Acta Geodaetica et Cartographic Sinica 43(3):226-232 (in Chinese with English abstract)

GoogleEarth (2015) Google Earth. https://earth.google.com/. Google Inc. Accessed 2015

Hashemi M, Alesheikh AA (2011) A GIS-based earthquake damage assessment and settlement methodology. Soil Dyn Earthq Eng 31(11): 1607-1617

IRIS (2015) Seismic monitor. http://ds.iris.edu/seismon/. Incorporated Research Institutions for Seismology (IRIS). Accessed 2015

JMA (2015) Earthquake information. http://www.jma.go.jp/en/ quake. Japan Meteorological Agency,Tokyo, Japan (JMA). Accessed 2015
Kresse W, Danko DM (2012) Springer handbook of geographic information. Springer, Berlin, pp 118-120

Nadi S, Delavar MR (2003) Spatio-temporal modeling of dynamic phenomena in GIS. Scandinavian Research Conference on Geographical Information Science-ScanGIS, Espoo, Finland, pp 215-225

NASA World Wind (2014) World wind. http://worldwind.arc.nasa. gov. The National Aeronautics and Space Administration (NASA). Accessed 2014

Obe R, Hsu L (2011) PostGIS 2.0 raster and 3D support enhancements (report). North Carolina GIS conference

OSGeo (2010) PostGIS 2.0.0 manual. http://postgis.net/docs/manual2.0/

Paar P, Clasen M (2007) Earth, landscape, biotope, plant. Interactive visualisation with biosphere 3D. International conference on urban planning and regional development in the information society. Eigenverlag des Vereins CORP, Vienna, May 20-23, 2007

Peng H, Wu Z, Wu YM, Yu S, Zhang D, Huang W (2011) Developing a prototype earthquake early warning system in the Beijing capital region. Seismol Res Lett 82(3):394-403

Pessina V, Meroni F (2009) A WebGIS tool for seismic hazard scenarios and risk analysis. Soil Dyn Earthq Eng 29(9):1274-1281

Saadatseresht M, Mansourian A, Taleai M (2009) Evacuation planning using multiobjective evolutionary optimization approach. Eur J Oper Res 198(1):305-314

Sato HP, Harp EL (2009) Interpretation of earthquake-induced landslides triggered by the 12 May 2008, M7.9 Wenchuan earthquake in the Beichuan area, Sichuan Province, China using satellite imagery and Google Earth. Landslides 6(2):153-159

Shi R, Xu H, Chen H (2008) Application of 3D VirtualWebGIS in earthquake disaster prevention and mitigation. J Seismol Res 31(2):193-196 (in Chinese with English abstract)

USGS/NEIC (2014) Latest earthquakes. http://earthquake.usgs.gov/ earthquakes/map/. National Earthquake Information Center (NEIC). Accessed 2014

WebGL (2013) WebGL specification, version 1.0.2. https://www. khronos.org/registry/webgl/specs/1.0.2/. Accessed 1 Mar 2013

World Wind Java SDK (2011) NASA World Wind Java SDK. http:// worldwind.arc.nasa.gov/java/. The National Aeronautics and Space Administration (NASA). Accessed 2011

X3D (2015) X3d. Wikipedia. http://en.wikipedia.org/w/index.php?ti tle $=X 3$ D \&oldid $=643179479$. Wikimdedia project. Accessed 2015

Yang C, Huang Z (2009) Earthquake instant messenger system in China. Seismol Geomagn Obs Res 30(5):133-138 (in Chinese with English abstract)

Yu L, Gong P (2012) Google Earth as a virtual globe tool for earth science applications at the global scale: progress and perspectives. Int J Remote Sens 33(12):3966-3986

Zerger A, Smith DI (2003) Impediments to using GIS for real-time disaster decision support. Comput Environ Urban Syst 27(2):123-141 